\title{
Um teste de quebra estrutural para a hipótese de deslocamento do centro dinâmico na indústria brasileira nos anos 1930
}

\author{
A Structural Break Test to the Hypothesis of Displacement of the Dynamic \\ Center in Brazilian Industry in the 1930's
}

\author{
Leonardo Segura Moraes, Jonattan Rodriguez Castelli e Leonel Toshio \\ Clemente $^{*}$
}

\begin{abstract}
Resumo: Este artigo busca oferecer evidências empíricas sobre a hipótese furtadiana de deslocamento do centro dinâmico na economia brasileira nos anos 1930, a qual entende a crise de 1929 como um fenômeno impactante sobre dinâmica econômica brasileira, especialmente à produção industrial. Para testar empiricamente essa hipótese, estimou-se um modelo de tendência pelo método de Mínimos Quadrados Ordinários para o índice do PIB industrial brasileiro entre 1900 e 1947, e foram testadas quebras estruturais por meio do teste Quandt-Andrews. Os resultados indicam quebra estrutural em 1929, durante a Grande Depressão. Portanto, rejeitou-se a hipótese de que o padrão de crescimento do PIB industrial brasileiro entre 1900 e 1947 foi estável. Entende-se que esse período foi um processo de transformações institucionais profundas na economia brasileira. A análise empírica foi corroborada pela revisão da literatura sobre mudanças institucionais e intencionalidade industrializante da política econômica.
\end{abstract}

Palavras-Chave: Industrialização; Deslocamento do centro dinâmico; Celso Furtado

\begin{abstract}
This paper aims to provide empirical evidence on the Furtadian hypothesis of displacement of the dynamic center in the Brazilian economy in the 1930s, which understands the crisis of 1929 as a shocking phenomenon on Brazilian economic dynamics, especially regarding the industrial production. To empirically test this hypothesis, we applied a trend model by the Ordinary Least Squares method for the Brazilian industrial GDP index between 1900 and 1947, additionally, structural breaks were tested using the Quandt-Andrews test. The results indicate a structural break in 1929, during the Great Depression. Therefore, the hypothesis of stable growth pattern of the Brazilian industrial GDP between 1900 and 1947 was rejected. This period is understood as a process of deep institutional transformations in the Brazilian economy. The empirical analysis was corroborated by the literature review on institutional changes and industrializing intentionality of economic policy.
\end{abstract}

Keywords: Industrialization; Displacement of the dynamic center; Celso Furtado

JEL Code: N01; N16

\footnotetext{
* Respectivamente, Professor adjunto da Universidade Federal de Uberlândia (UFU) e pesquisador do NEPPAS/UFRGS. E-mail: lseguram@hotmail.com; Professor adjunto da Universidade Estadual de Mato Grosso do Sul (UEMS). E-mail: castellijonattan@gmail.com; e Professor adjunto da Universidade Federal do Rio Grande do Sul (UFRGS). E-mail: leonel t_clemente@hotmail.com. DOI: http://dx.doi.org/10.5380/re.v40i72.68190
} 


\section{Introdução}

A historiografia econômica brasileira se divide no que tange à década de 1930 e os significados que a Revolução de 1930 teve sobre a dinâmica da produção e distribuição material da vida no país. Perguntas como: "houve alguma consciência industrializante por parte do governo Vargas I?", ou "a política econômica implementada a partir de 1930 foi ortodoxa ou heterodoxa?", ou então "é possível afirmar que a década de 1930 representa um ponto de inflexão no desenvolvimento econômico brasileiro?" permeiam o debate.

Responder essas perguntas é de suma importância para aprofundar o entendimento sobre as transformações da economia brasileira na década de 1930 e para compreender o significado da industrialização por substituição de importações. Não há consenso se essa década representa um ponto de inflexão na economia brasileira. Furtado ([1959] 2009) argumenta que a política de defesa do café foi a responsável pelo crescimento industrial do país e também pelo fato de Brasil ter sido um dos primeiros a sair da crise. No entanto, para Furtado (2009), tal política ocorreu sem intencionalidade industrializante por parte do governo Vargas. Por outro lado, Peláez (1972) argumenta que não há alteração substancial na industrialização brasileira nos anos 1930, pois a política anticíclica implementada não teve impacto significativo sobre a industrialização. O indicador de industrialização analisado por Peláez (1972) é a capacidade produtiva.

A tese apresentada por Furtado (2009) no conhecido capítulo 32 de sua obra Formação Econômica do Brasil é conhecida como o deslocamento do centro dinâmico da economia brasileira para o mercado interno a partir dos anos 1930. A partir dessa tese, entende-se que a política de valorização do café, levada a cabo por Vargas, constituiu-se inconscientemente como um programa de fomento à renda nacional, na medida que ao não se financiar por meio de empréstimos externos, operacionalizou uma solução na qual se instituiu um imposto sobre o café exportado ${ }^{2}$. Num contexto de dupla crise tanto do lado da oferta como da demanda pelo produto, essa solução acarretou em manter o nível de emprego na economia ao propiciar maior criação de renda do que de valor destruído.

\footnotetext{
2 É preciso considerar também a questão da intencionalidade da política econômica elaborada e executada pelo governo Vargas nos anos 1930. Fonseca (2003) analisa a intencionalidade e a consciência da ação econômica de Estado no que tange à consecução de políticas industrializantes vis-à-vis às taxas de crescimento da indústria de transformação ao longo dos anos 1930 e conclui que a opção industrializante não foi sem querer, mas gestada conscientemente pelo governo.
} 
De acordo com a tese furtadiana, a consequência dessa política de valorização do café implementada pelo governo Vargas na década de 1930 em um contexto de depressão econômica alterou bruscamente os preços relativos das importações. Desse modo, ao promover uma política de defesa do café na conjuntura adversa da década de 1930, tanto em termos de financiamento externo quanto de expansão das exportações, houve um fortalecimento no setor interno da economia brasileira, aproveitando a capacidade produtiva instalada no país. Portanto, o deslocamento do centro dinâmico corresponde aos efeitos estruturais na produção brasileira, oriundos do tratamento distinto na política de valorização do café do governo Vargas em relação ao que se praticava desde o Convênio de Taubaté, em 1906, isto é, endividamento externo para financiar ajuste recessivo.

Para Prado Jr. ([1945] 2012), a década de 1930 representa uma fase de mudança para o Brasil, mas o autor entende que essa mudança se deu por meio de desequilíbrios na conta de capital brasileira e que a Revolução de 1930 significou a reafirmação da condição de colônia do país. Nessa interpretação, as transformações em curso ao longo dessa década teriam sido uma atualização da posição dependente da economia brasileira no mercado mundial capitalista. Portanto, Caio Prado Jr. se mostra menos entusiasmado com a industrialização brasileira nos anos 1930.

Uma tentativa de síntese do debate foi elaborada por Versiani e Versiani (1978), segundo os quais o período compreendido entre 1921 e 1930 foi de aumento significativo da capacidade produtiva da economia brasileira. Desse modo, se a explicação de Furtado sobre o crescimento industrial pós 1930 não explicava a origem dessa capacidade produtiva, e era assim criticada, por exemplo, por Peláez (1972), já Versiani e Versiani (1978) relacionavam a industrialização aos fenômenos históricos da década de 1930 de modo a também dar razão a tese furtadiana.

Com base no debate apresentado, testar a hipótese de deslocamento do centro dinâmico é fundamental para entendermos a história da indústria brasileira. Portanto, este artigo busca testar a presença de quebra estrutural no PIB industrial brasileiro ao longo dos anos 1930, especialmente nos anos imediatamente posteriores a crise de 1929. A hipótese a ser testada é se a dinâmica da economia brasileira, a partir da chamada Revolução de 1930, teve alteração estrutural. A variável analisada será o PIB industrial brasileiro entre 1900 e 1947. 
Para tanto, este artigo conta com seis seções, incluindo esta introdução. $\mathrm{Na}$ segunda seção será apresentada, sucintamente, a abordagem institucionalista de Geoffrey Hodgson, a fim de trazer à baila os principais conceitos utilizados na análise teórica deste artigo. Na terceira seção, por sua vez, descrever-se-á a metodologia econométrica aplicada, enquanto a quarta seção apresenta a estimação do modelo de tendência com quebra estrutural para a produção industrial brasileira. $\mathrm{Na}$ quinta seção será apresentada uma interpretação econômica dos resultados do modelo. Por fim, na sexta seção apresentamos as considerações finais e indicação para continuidade da pesquisa.

\section{A teoria institucional de Geoffrey Hodgson}

A teoria institucionalista, desenvolvida inicialmente por Veblen e pelo antigo institucionalismo norte-americano, tem ocupado um papel cada vez mais destacado na teoria econômica. Em razão da miríade de correntes dentro da perspectiva institucionalista, optou-se, neste trabalho, por fazer uso da abordagem de Geoffrey Hodgson. Seguindo a tradição vebleniana, as instituições são definidas como sendo um "sistema de regras sociais estabelecidas e prevalecentes que estruturam as interações sociais" (Hodgson, 2006, p. 2), como, por exemplo, as leis, a moeda, o sistema de peso e medidas, a linguagem e as firmas.

Mais do que isso, na teoria de Hodgson, as instituições e os indivíduos se confundem. As instituições nascem da interação entre os indivíduos, mas também moldam essa interação e a forma como os agentes econômicos se comportam. Isto é, “as instituições moldam e são moldadas pela interação humana, elas são tanto ideias subjetivas na cabeça dos agentes quanto estruturas objetivas encaradas por eles" (Hodgson, 1998, p. 181, tradução nossa).

A matéria que constitui as instituições, por outro lado, seriam os hábitos. Os hábitos dos indivíduos reforçam e são reforçados pelas instituições sociais. Entretanto, Hodgson (2006) ressalta que os hábitos são adquiridos no contexto social, e não pela transmissão genética hereditária. Eles se derivam de comportamentos repetidos dos indivíduos. A origem dos hábitos de um indivíduo pode residir tanto em uma disposição inata quanto ou mesmo na tendência de imitar o comportamento dos outros agentes em um contexto social específico. Destarte, o hábito é em sua essência um resultado da interação social. 
O processo de transformação institucional das estruturas socioeconômicas se principia, como aventado por Veblen (1965), na mudança dos hábitos de pensamento e na ação dos agentes econômicos que se adaptam às novas condições ambientais e materiais de uma sociedade. A transformação do arranjo institucional aparece nos escritos de Veblen, a partir de sua análise da causação cumulativa, ou seja, uma ação, mudança, estabelece uma nova situação que sofrerá, com o passar do tempo, novas alterações levando a uma nova situação, de maneira que sempre o fantasma do passado se manifesta no presente.

No princípio, há um conjunto de instintos e um estilo de vida definido, com hábitos de pensamento e instituições estabelecidas. Com o tempo, o arranjo institucional pode mudar como resposta a uma alteração na forma como os indivíduos interagem nas suas atividades econômicas e sociais, e, principalmente, por alguma alteração nas bases materiais da sociedade, como o surgimento de novas tecnologias. Os indivíduos se adaptarão às novas condições materiais, mudando seu estilo de vida e hábitos de pensamento e de ação.

À medida que os novos hábitos tomem o lugar dos antigos, serão constituídas novas instituições, que substituirão aquelas que forem incompatíveis com a nova realidade, assistindo, assim, a alvorada de uma nova estrutura institucional. Desta maneira, a mudança institucional ocorre através do desuso e da substituição de antigos por novos hábitos, promovidos pelo novo ambiente material. Primeiro, as crenças dos indivíduos se alteram, a partir de uma mudança na base material da sociedade, e, depois, elas se tornam hábitos, os quais são convencionados como instituições.

Figura 1 - Reconstitutive Downward Causation

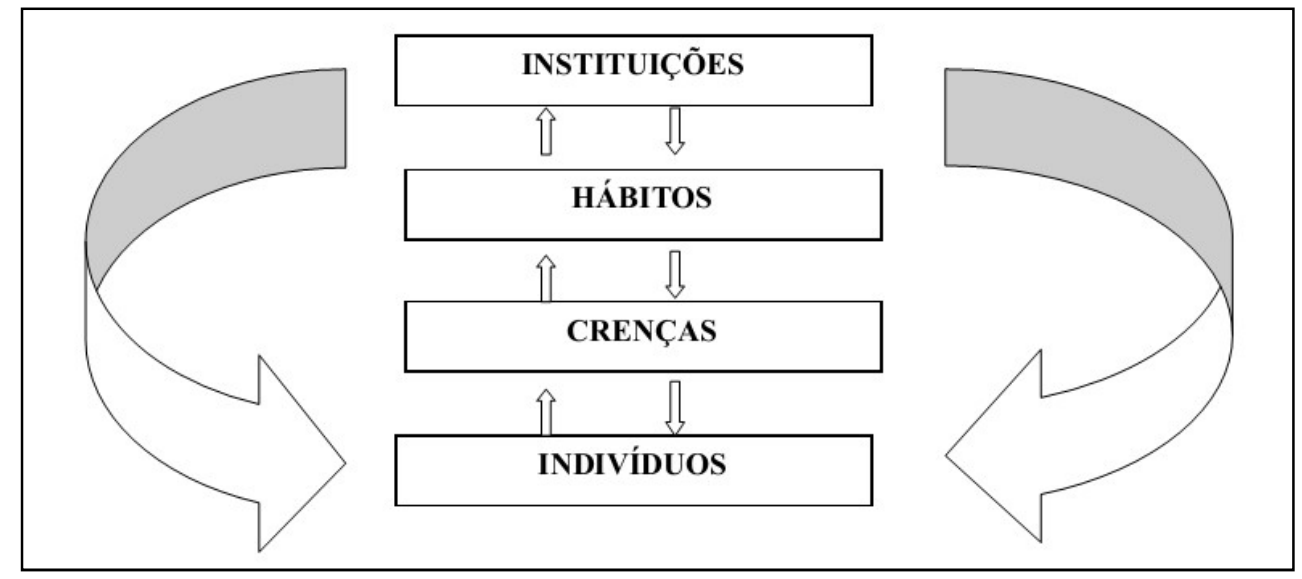

Fonte: elaborado pelos autores a partir de Hodgson (2006). 
Todavia, as novas instituições podem alterar as crenças e hábitos dos indivíduos, delimitando um processo de causação circular da transformação do arranjo institucional, denominado por Hodgson (2006) como Reconstitutive Downard Causation, que pode ser observado na figura acima. As setas apontadas para cima representam os estímulos geradores do nível superior e as setas apontadas para baixo, assim como as duas grandes setas laterais, representam o feedback de cada nível superior para o inferior.

O processo de mudança institucional, sem embargo, não é um fenômeno teleológico ou mesmo previsível. Apesar de amiúde este ocorrer concomitantemente à transformação ambiental, ele é marcado pela inércia. Instituições que estão profundamente enraizadas nos hábitos de pensamento e de comportamento dos indivíduos tendem a se perpetuar mesmo diante de uma mudança material - como a ocorrência de uma revolução tecnológica. Destarte, à medida que instituições arcaicas se perpetuam - i.e. aquelas que não estão ligadas à nova concretude do sistema econômico, mas ao modo de produção anterior cria-se uma dependência da trajetória no crescimento e desenvolvimento dos países.

Por conseguinte, as trajetórias de crescimento são criadas historicamente, partindo da trajetória de desenvolvimento das instituições nacionais que, muitas vezes, já estão enraizadas na estrutura socioeconômica (ZYSMAN, 1994). Destarte, a história importa, o desenvolvimento das nações distinguir-se-ia por estar assentado em um conjunto de instituições distintas. No entanto, as instituições não podem ser escolhidas racionalmente, não sendo um mero regramento, mas são estruturas sociais que têm origem nos hábitos dos indivíduos e que, por isso, são difíceis de serem alteradas.

Existe, portanto, uma dependência de trajetória (path dependence), decorrente do processo de mudança e de continuidade das suas instituições dos países. A construção do arranjo institucional de um país é realizada historicamente, através por meio da interação dos agentes econômicos e pela seleção daquelas instituições que melhor se adaptam a uma realidade material - embora instituições arcaicas possam permanecer na estrutura socioeconômica -, e não pela cópia de modelos estrangeiros. $\mathrm{O}$ ato de emular uma lei, regra ou política que, no entanto, não encontre aderência nos hábitos de pensamento dos agentes econômicos, está fadada ao fracasso e a não ser institucionalizada. 
Ademais, o espaço para o Estado ser um propositor do arranjo institucional acaba por ser mais limitado do que em outras abordagens, embora assuma um papel destacado para sua sustentação. De acordo com Hodgson (2015), o aparato legal não emerge de maneira espontânea a partir da interação entre os indivíduos, especialmente em sociedades hierarquizadas e complexas, em que os agentes econômicos não compartilham as mesmas motivações. Existe um processo de seleção das instituições, em que o poder político-econômico de uma classe social pode prevalecer ante as demais e pesar na construção do aparato legal, combinado a isso, existe a utilização simbólica de mitos autorizados que possibilitam a aceitação dele pelo resto da sociedade.

Sem embargo, torna-se mister a ação do Estado, detentor do monopólio da violência em uma sociedade, para que as leis cumpram seu papel e sejam respeitadas. Sem contar que o próprio Estado não é monolítico, mas uma arena de disputa política, em que as divergências de interesse social sintetizar-se-iam.

Desse modo, a alteração do arranjo institucional também passa pelos meandros do jogo político dentro do Estado. A despeito de as instituições serem reflexo dos hábitos compartilhados socialmente - o que a priori excluiria a ação estatal para sua legitimação -, o Estado transforma hábitos e costumes em leis, a partir da resolução de brechas, imprecisões e disputas (HODGSON, 2015). Consequentemente, a seleção dessas convenções, que assumirão a forma de leis, depende da visão de mundo, estratégia de desenvolvimento e relação entre o Estado e a sociedade. Ignorar esses aspectos na análise de políticas econômicas assentadas na mudança institucional é deixar de lado um ponto central para compreendê-las.

\section{Metodologia de estimação do modelo de tendência com quebra estrutural}

Para testar a hipótese de quebra estrutural, propõe-se estimar um modelo de mínimos quadrados ordinários do PIB industrial dividido pelo PIB brasileiro contra o tempo e realizar testes de estabilidade para esse modelo de tendência. $\mathrm{O}$ teste de estabilidade que será realizado é teste Quandt-Andrews. Esse teste baseiase no clássico teste de Chow para quebra estrutural, estimando testes de Chow para um intervalo de tempo e, a partir disto, calculando um teste F para identificação de 
um ponto de quebra. O teste Quandt-Andrews exime o pesquisador da responsabilidade de arbitrar à priori uma data possível de quebra estrutural.

No modelo proposto, o regressando é a razão entre PIB industrial e PIB brasileiro, ambos em termos nominais e originalmente em forma de índice $(1901=100)$. Optou-se por utilizar essa razão, denominada pela sigla PIND, para remover os efeitos do aquecimento da produção como um todo sobre a produção industrial e, além disso, para remover o efeito da inflação. Posteriormente, a variável PIND foi transformada em índice. Deve-se destacar que as mudanças em preços relativos entre produtos industriais e os demais preços podem gerar distorções na razão entre PIB industrial e PIB brasileiro.

Os dados de PIB industrial e PIB brasileiro foram calculados por Haddad ${ }^{3}$ apud IPEADATA (2019). As séries foram denominadas pelo autor como "Produto interno bruto (PIB) - indústria: índice (média $1939=100$ )" e "Produto interno bruto (PIB) a preços constantes de 1947”, respectivamente. Os dados anuais são referentes ao período entre 1901 e 1947. Esta amostra pequena limita a aplicação de métodos mais sofisticados tanto de identificação dos padrões de comportamento $^{4}$ de PIND quanto nos testes de quebra estrutural. Por isso, escolheu-se o método simples de Mínimos Quadrados de estimação de tendência utilizando o software Eviews 9.0.

\section{Modelo de tendência com quebra estrutural}

A estimação do modelo de tendência temporal identificou uma tendência de crescimento para PIND (razão do PIB industrial sobre PIB brasileiro). A equação estimada foi:

$$
P I N D=-39,5+0,000005 * \text { TIME }
$$

em que: PIND = Razão entre PIB industrial e PIB

$$
\text { TIME }=\text { Variável tempo }
$$

\footnotetext{
${ }^{3}$ HADDAD, Claudio Luiz da S. Crescimento do produto real no Brasil, 1900-1947. FGV-RJ, 1978.

4 Testou-se modelagem ARIMA com até 3 defasagens. A série PIND é estacionária em sua primeira diferença, e o modelo com maior critério de Akaike foi o ARIMA $(0,1,0)$. Esse fenômeno pode decorrer do tamanho da amostra, pois não há sentido em assumir que a série PIND não tem padrões sistemáticos além da taxa de crescimento.
} 
Esta regressão teve coeficiente de determinação de $85 \%$ e todos os coeficientes significativos a $99 \%$ de confiança. A realização do teste de quebra estrutural excluiu os $15 \%$ iniciais e $15 \%$ finais da amostra. O resultado obtido foi:

\section{Tabela 1 - Teste De Quebra Estrutural De Quandt-Andrews}

\begin{tabular}{|lll|}
\hline $\begin{array}{l}\text { Amostra: 1901 a } 1947 \\
\text { Sub-amostra: } 1909 \text { a } 1940\end{array}$ & & \\
\hline \hline Valor & p-valor \\
\hline \hline F-calculado para 1929 & 96.71560 & 0.0000 \\
\hline \hline
\end{tabular}

Fonte: elaborado pelos autores.

A hipótese nula é de que não há quebra estrutural entre 1909 e 1940 . O pvalor calculado para o teste de Wald baseia-se em Hansen (1997) e identificou quebra estrutural em 1929 com 99\% de confiança. O valor da estatística F para 1929 foi o maior entre os pontos de quebra estrutural testados. Para averiguar como se deu a quebra estrutural identificada no teste de Quandt-Andrews, inseriu-se no modelo de tendência a dummy de mudança estrutural em 1929, cujos valores são zero para antes de 1929 e um para 1929 em diante. Essa dummy foi inserida na forma aditiva e na forma multiplicativa, o que gerou a seguinte estimação:

Tabela 2 - Estimação Do Modelo De Tendência Com Dummy

\begin{tabular}{|c|c|c|c|c|}
\hline \multicolumn{5}{|c|}{$\begin{array}{l}\text { Variável dependente: PIND } \\
\text { Mínimos Quadrados Ordinários } \\
\text { Número de Observações: } 47\end{array}$} \\
\hline Variável & Coeficiente & D.P. $\quad t$ & t -calculado & p-valor \\
\hline TIME & $6.26 \mathrm{E}-05$ & $4.95 \mathrm{E}-06$ & 12.62570 & 0.0000 \\
\hline TIME*D29 & $7.16 \mathrm{E}-05$ & $1.26 \mathrm{E}-05$ & 5.665543 & 0.0000 \\
\hline D29 & -50.78240 & 8.930480 & -5.686414 & 0.0000 \\
\hline $\mathrm{C}$ & -42.38152 & 3.464554 & -12.23289 & 0.0000 \\
\hline R-squared & 0.931370 & & & \\
\hline
\end{tabular}

Fonte: elaborado pelos autores. 
Constata-se que os coeficientes da dummy foram significativos tanto na forma aditiva quanto multiplicativa. Portanto, a quebra estrutural de 1929 representou tanto uma mudança no patamar da série de PIND quanto uma mudança na tendência desta variável. Tendo em vista que o coeficiente da dummy aditiva foi negativo, constata-se um impacto negativo imediato na PIND nesse ano. Porém, tendo em vista que o coeficiente da dummy multiplicativa foi positivo, entende-se que houve uma aceleração da industrialização desde então.

\section{Interpretação econômica}

Em termos gerais, as evidências empíricas aqui apresentadas se dirigem especialmente à interpretação estruturalista da industrialização brasileira. Nessa visão, o choque adverso da crise de 1929 teria impactado favoravelmente à afirmação das indústrias de bens de consumo tradicionais existentes no país, pois teria sido um meio pelo qual a gestação prévia da acumulação de tipo industrial encontrou forma de se expandir, ainda que a dualidade típica entre os setores moderno e atrasado permanecesse. Um fenômeno intrigante no momento da quebra é a queda do índice da formação bruta de capital fixo em máquinas e equipamentos, como mostra o gráfico 1.

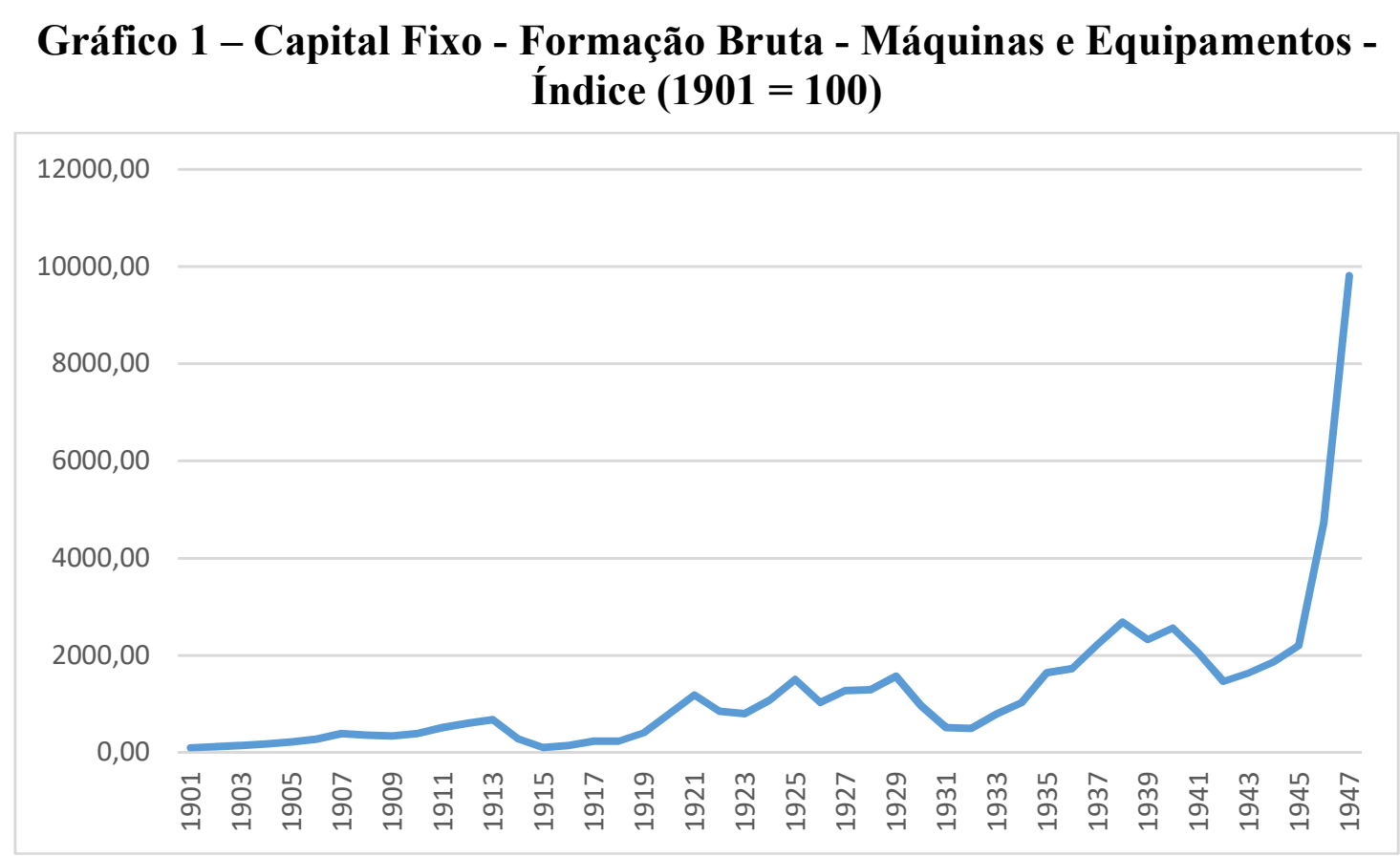

Fonte: Elaborado pelos autores a partir de Ipeadata. 
Para Versiani e Versiani (1978), esse resultado indica que as medidas de política econômica tomadas frente a crise de 1929 não indicam aumento da capacidade produtiva. Foi somente a partir de 1945, no contexto da Segunda Guerra Mundial, que houve uma mudança extraordinariamente positiva no patamar da formação bruta de capital fixo. Portanto, o surto de crescimento industrial após a Revolução de 1930 parece estar condicionado à maior utilização de capacidade produtiva preexistente na economia brasileira (MARSON, 2015).

Analisar a existência de quebra estrutural do PIB industrial contribui para avaliar os significados dos eventos políticos e econômicos ocorridos nas décadas de 1920 e 1930 no Brasil. Afinal, se a ascensão de Getúlio Vargas ao poder representa uma ruptura política com os interesses do setor atrasado (basicamente rural), é de se esperar que haja algum impacto da produção industrial do país (setor interno). O ponto de quebra estrutural identificado no ano de 1929 não significa que o deslocamento do centro dinâmico da economia brasileira ocorreu imediatamente. As medidas econômicas implementadas a partir de 1930, como resposta ao choque adverso (Grande Depressão de 1929), assim como a dinâmica da correlação de forças políticas internas e sua ruptura constitucional, apresentam certo tempo de resposta para se efetivarem sobre a produção industrial.

A performance econômica dos países é historicamente determinada pela dinâmica das instituições (NORTH, 1994), aspecto que se complementa com a evidência encontrada neste trabalho. Isso significa que as mudanças implementadas a partir de 1930 não necessariamente iriam se efetivar no mesmo ano, embora possam indicar um novo padrão da dinâmica industrial brasileira (FONSECA, 2003; BASTOS, 2006).

Nesse sentido, o conceito de reconstitutive downward causation, discutido na seção 2, sublinha que o processo de transformação de um arranjo institucional não é algo que ocorra apenas pela mera adoção de novas regras e leis, já que estas precisam encontrar aderência nos hábitos de pensamento e comportamento compartilhados socialmente. De tal maneira que, a alteração estrutural do ambiente econômico e institucional - deslocamento do centro dinâmico - propiciado pela crise de 1929, pelas políticas “keynesianas antes de Keynes” e adotadas por Vargas -, levou certo tempo para afetar os hábitos compartilhados na sociedade brasileira.

Destarte, pode-se identificar três aspectos que afetaram o arranjo institucional brasileiro e possibilitaram essa quebra estrutural: 
i) a crise de 1929 e seus efeitos no preço do café - tema discutido na obra clássica de Celso Furtado;

ii) as políticas econômicas e criação e modificação de regras e leis por Vargas nos anos 1930;

iii) e uma base habitual industrializante e burguesa, ligada tanto a partir da entrada de imigrantes no país quanto pela adoção de práticas de produção mais modernas pelos latifundiários brasileiros.

O primeiro aspecto não será aqui discutido, por já ter sido abordado na introdução deste artigo e ser a reconhecida e amplamente discutida tese de Furtado em Formação Econômica do Brasil, apresentada nos capítulos 30 a 32 desta obra. Logo, discorrer-se-á sobre os outros dois aspectos.

No tocante às mudanças institucionais promovidas por Vargas, Fonseca (2003) argumenta favoravelmente a essa hipótese a partir do estudo da política econômica relacionada à intencionalidade industrializante da gestão Vargas no país ${ }^{5}$. Em suas palavras,

Pode-se demonstrar que as instituições criadas elou modificadas na década de 1930 pelo governo brasileiro evidenciam sua opção industrializante, pois representam mecanismos, regras, arenas e espaços para, dentro do aparelho estatal e sob sua influência, reorientar a economia, definindo uma nova relação estado/empresariado/mercado/trabalhador (FONSECA, 2003, p. 135).

Entre as mudanças institucionais elencadas pelo autor, destaca-se o Decreto 19.739, de março de 1931, o qual "proibia a importação de máquinas e equipamentos para certos segmentos da indústria" (FONSECA, 2003, p. 141); além disso, a Reforma Tributária de 1934 revela também o caráter protecionista à indústria nacional e o Tratado de Comércio com os EUA em 1935, que mostra a intenção governamental de romper com o antigo papel de importador de bens de capital e insumos por meio da redução de $20 \%$ a $60 \%$ desses bens na pauta importadora do Brasil em relação aos EUA; por fim, há a evidência também nos discursos de Vargas sobre a necessidade de protecionismo em relação à indústria brasileira nascente (FONSECA, 2003, p. 142-143).

\footnotetext{
5 Destaca-se, por exemplo, o crescimento anual de 11,2\% do produto industrial entre 1933 e 1939 (VILLELA; SUZIGAN, 1973, p. 211-212).
} 
A respeito do terceiro aspecto, Fonseca (2003) afirma que a industrialização passa a ser entendida como um sinônimo para o desenvolvimento. Por conseguinte, essa noção estimulou o surgimento de novas crenças, valores, símbolos e padrões de comportamento. Em outras palavras, houve o estabelecimento de uma base habitual que sustentasse institucionalmente, a partir dos hábitos compartilhados socialmente, o processo de industrialização.

Segundo Lopes (2014, p.105), essas novas crenças e o novo modelo ideológico pró-industrialização "não poderiam surgir sem a existência de conflitos e contradições de um passado agrário e semicolonial com a 'moderna' mentalidade de mercado, que estaria por se formar a partir do crescimento do mercado interno".

Conforme o autor, essa mudança de mentalidade durante o período em favor da industrialização possuiria três pilares:

i) a entrada de imigrantes europeus na região do estado de São Paulo, os quais traziam consigo um viés industrial e, muitas vezes, algum capital próprio que serviu de base para investimentos produtivos, como atestam Warren Dean (1971), de Florestan Fernandes (1981) e de Bresser-Pereira (1994);

ii) a adoção de práticas mais "modernas" de produção pela classe latifundiária. Consoante Dean (1971), os novos industriais particularmente os europeus - representavam uma ameaça aos interesses econômicos e ao poder político (representativo junto ao Estado) dos latifundiários tradicionais. Temia-se que a consolidação industrial provocasse um deslocamento de capitais e de trabalhadores para esse setor, em detrimento do agroexportador (LOPES, 2014). Assim sendo, Lopes (2014) observa que embora a mudança de mentalidade fosse incômoda, muitos fazendeiros compreenderam que se inserir na nova forma de produção seria a única maneira de prosperar, à medida que esta já se sobrepunha ao retrógrado setor cafeeiro ${ }^{6}$;

iii) o discurso de Vargas pró-desenvolvimento via industrialização, pois havia um engajamento e uma intencionalidade desse presidente em enfatizar a

\footnotetext{
${ }^{6}$ Segundo Florestan Fernandes (1981), o imigrante introduziu uma forma de ser, de pensar e de agir na qual o cálculo econômico e racionalidade se sobressaíam, enquanto o fazendeiro de café sofreu transformações de personalidade, mentalidade e comportamento prático tão profundas e radicais que ele se converteu de coronel a homem de negócios.
} 
priorização do desenvolvimento industrial, mesmo sem abandonar o setor primário - aspecto destacado por Fonseca (2003).

Destarte, observa-se que a conjuntura econômica de restrição externa causada pela crise de 1929 e as políticas implementadas por Vargas para estimularem a indústria nascente têm um efeito irruptivo, à medida em que eles estavam assentados em uma base habitual - uma mentalidade pró-indústria - que vinha se estabelecendo no País desde o final do século XIX, com a entrada dos imigrantes europeus e com a transmutação dos senhores do café em empresários industriais. Mudanças que eram reforçadas pelo discurso do próprio governo de Vargas. A partir da noção de reconstitutive downward causation, pode-se sugerir que esses elementos possibilitaram que as alterações no regramento formal tivessem aderência nos hábitos de pensamento e comportamento compartilhados socialmente.

Esse processo, por sua vez, não se dá de forma instantânea, necessitando algum tempo de acomodação. A partir disso, entende-se que a quebra estrutural encontrada pelo modelo econométrico aplicado nesse artigo se deu em 1929, fato que nos permite afirmar que não é possível rejeitar a hipótese furtadiana do deslocamento do centro dinâmico da economia brasileira nos anos 1930. Outrossim, tal quebra não se processou imediatamente, mas caracterizou um momento decisivo para uma dinâmica em processo de constituição. Isso se deu em razão do tempo de acomodação para que as políticas econômicas e o novo regramento pró-indústria aderissem nos hábitos de pensamento e comportamento dos indivíduos.

\section{Considerações finais}

Um teste de quebra estrutural para a indústria brasileira com o intuito de testara hipótese de deslocamento do centro dinâmico na década de 1930, constatou quebra exatamente no ano de 1929 e, portanto, sugere que os anos imediatamente após a Grande Depressão e a Revolução de 1930 indicam a presença de mudança de nível para o índice do PIB industrial no país.

Entende-se que avaliar a tese furtadiana do deslocamento do centro dinâmico como hipótese de pesquisa não se resume a uma análise quantitativa, 
pois a dinâmica das economias reflete a interação de aspectos políticos e econômicos, os quais não necessariamente respondem imediatamente às mudanças. Sendo assim, a quebra estrutural para o ano de 1929 pode ser vista de acordo à proposição de que a década de 1930 representa um ponto de inflexão no desenvolvimento econômico do Brasil. Nesse sentido, destaca-se a Constituição promulgada no ano de 1934, que sinaliza a legitimação política da correlação de forças que assumiu o poder a partir da ruptura com a República Velha marcada pela ascensão de Vargas. Se, por um lado tal ruptura não se caracteriza como superação do sentido da colonização, não se sustenta afirmar que esse período apresenta ausência de transformações estruturais na economia e sociedade brasileira. Estas podem ser vistas a partir da intencionalidade industrializante do governo Vargas e do arranjo político que sustentou o sentido da ação econômica de Estado ao longo da década.

É preciso, no entanto, destacar que o exercício econométrico proposto é simplificado e quaisquer conclusões além do que foi indicado precisam ser feitas sob maiores evidências empíricas. Como sugestão para futuros trabalhos, indicase a possibilidade de utilização de outros testes de quebra estrutural, e uma modelagem mais robusta para avaliar o PIB industrial no período a partir da inclusão de uma periodicidade maior e de variáveis que captem as demais influências sobre o PIB, tais como o investimento externo direto e as taxas de lucro em segmentos industriais. Mais do que isso, e como hipótese mais avançada, a proposição aqui feita poderia ser testada para os demais países latino-americanos, a fim de avaliar os impactos do choque adverso de 1929 sobre a dinâmica de suas economias.

\section{Referências}

BASTOS, P. P. Z. A construção do nacional-desenvolvimentismo de Getúlio Vargas e a dinâmica de interação entre Estado e mercado nos setores de base. EconomiA, v. 7, n. 4, p. 239-275, 2006.

BRESSER-PEREIRA, L. C. Empresários, suas origens, e as interpretações do Brasil. 1994. Disponível em: <http://bibliotecadigital.fgv.br/dspace/bitstream/ handle/10438/1987/TD31.pdf;jsessionid=57B3820B31BDC3967C703299EE58A E3C? sequence=1>. Acesso em: 20 fev. 2019. 
DEAN, W. A Industrialização de São Paulo (1880-1945). São Paulo: Difusão Europeia do Livro e Editora Universidade de São Paulo, 1971.

FERNANDES, F. A revolução burguesa no Brasil. Rio de Janeiro: Zahar, 1981.

FONSECA, P. C. D. Sobre a intencionalidade da política industrializante no Brasil na década de 1930. Revista de Economia Política, v. 23, n. 1, p. 133-148, 2003

FURTADO, C. Formação econômica do Brasil. São Paulo: Companhia das Letras, 2009.

HODGSON, G. From Pleasure Machines to Moral Communities: An Evolutionary Economics without Homo economicus. Chicago: The University of Chicago Press, 2013.

HODGSON, G. The Approach of Institutional Economics. Journal of Economics Literature, v. 36, p. 166-192, 1998.

HODGSON, G. What are Institutions? Journal of Economic Issues, v. XL, n. 1, p. $1-25,2006$.

HODGSON, G. Conceptualizing Capitalism: Institutions, Evolution, Future. Chicago: University of Chicago Press, 2015.

IPEADATA. Crescimento do produto real no Brasil, 1900-1947. Disponível em: $<$ http://www.ipeadata.gov.br>. Acesso em: 01 Jun. 2019.

LOPES, H. C. A industrialização do Brasil nos anos 1930: uma interpretação institucionalista. Revista de Economia Política e História Econômica, ano 10, n. 32, p. 82-115, 2014.

MARSON, M. D. A industrialização brasileira antes de 1930: uma contribuição sobre a evolução da indústria de máquinas e equipamentos no estado de São Paulo, 1900-1920. Estudos Econômicos, v. 45, n. 4, p. 753-785, 2015.

NORTH, D. C. Economic performance through time. American Economic Review, v. 84, n. 3, p. 359-368, 1994.

PELÁEZ, C. M. História da industrialização brasileira. Rio de Janeiro: APEC, 1972.

PRADO JUNIOR, C. História econômica do Brasil. São Paulo: Brasiliense, 2012. 
VEBLEN, T. B. A Teoria da Classe Ociosa: um estudo econômico das instituições. São Paulo: Livraria Pioneira, 1965.

VERSIANI, F. R.; VERSIANI, M. T. R. O. A industrialização brasileira antes de 1930: uma contribuição. In: VERSIANI, F. R.; BARROS, J. R. M. Formação econômica do Brasil: a experiência da industrialização. São Paulo: Saraiva, 1978.

VILLELA, A.; SUZIGAN, W. Política do governo e crescimento da economia brasileira. IPEA/INPES, Rio de Janeiro, 1973.

ZYSMAN, J. How Institutions Create Historically Rooted Trajectories of Growth. Industrial and Corporate Change, v. 3, n. 1, p. 243-283, 1994. 